\title{
The contribution of autobiographical significance to semantic memory
}

\author{
ROBYN WESTMACOTT and MORRIS MOSCOVITCH \\ University of Toronto, Toronto, Ontario, Canada
}

\begin{abstract}
We examined the importance of autobiographical significance (AS) in the representation and organization of semantic memory by examining which famous people are most likely to be associated with specific personal memories and whether or not this AS can be distinguished from other factors, such as familiarity. Norming studies with 45- to 55-year-old and 65- to 80-year-old participants suggested that AS is distinct from familiarity and that it interacts closely with emotional salience. Furthermore, in a set of experiments, we tested the hypothesis that AS is an important organizing principle in long-term episodic and semantic memory by contrasting performances on tests of recall, recognition, fame judgment, and speeded reading for famous names judged to be of either high or low personal relevance. Participants demonstrated a performance advantage (i.e., enhanced memory and faster responding) for autobiographically significant famous names, regardless of whether their own judgments or others' judgments were used to classify the names. The implications of these findings for models of semantic memory are discussed.
\end{abstract}

In this paper, we explore the influence of autobiographical significance (AS) on the representation and organization of semantic memory. Specifically, we examined knowledge of famous names from 20th century North American culture in neurologically intact participants between the ages of 45 and 55 years and the ages of 65 and 80 years. We sought to determine whether some famous people are more likely than others to be associated with specific personal memories or to be relevant to one's personal experience and, if so, whether or not this AS can be distinguished from other factors that influence memory, such as frequency of exposure, recency, and emotion. Furthermore, we investigated whether AS is a determining factor on tests of episodic and semantic memory by contrasting experimental task performances for famous names judged to be of either high or low personal relevance.

Theories have emphasized the interdependence of $s e$ mantic and episodic memory (e.g., Cermak \& O'Connor, 1983; Hintzman, 1990; Larsen, 1992; McKoon, Ratcliff, \& Dell, 1986; Ratcliff \& McKoon, 1986; Van der Linden, de Partz, Schils, \& Seron, 1992), but little experimental research has been done to examine directly how autobiographical experience may contribute to the content and organization of semantic memory. Recent clinical observations of patients with semantic dementia have provided

This work was funded by Medical Research Council Grant MA-6694 to M.M. and a Canadian Institutes of Health Research Doctoral Scholarship to R.W. We thank Mary Pat McAndrews and Gus Craik for their contributions to this project. Correspondence concerning this article may be addressed to R. Westmacott or M. Moscovitch, Department of Psychology, University of Toronto, 100 St. George St., Toronto, ON, M5S 3G3 Canada (e-mail: robyn@psych.utoronto.ca or momos@ psych.utoronto.ca) compelling evidence that AS mitigates the disruptive effects of brain damage on semantic memory. Semantic dementia is a neurodegenerative disorder characterized by a multimodal breakdown of semantic memory that develops typically as the result of bilateral or left-lateralized atrophy of the anterior, inferior temporal neocortex. Patients demonstrate a profound anomia and a severe impairment in knowledge of objects, facts, concepts, and people (Bozeat, Lambon Ralph, Patterson, Garrard, \& Hodges, 2000; Graham \& Hodges, 1997; Hodges \& Graham, 1998; Hodges \& McCarthy, 1995; Hodges, Patterson, \& Tyler, 1994; Snowden, Goulding, \& Neary, 1989). However, some information appears to be more resistant to damage, remaining relatively intact until late stages of the disease. For example, memories seem to take on a highly personalized and idiosyncratic quality that is specific to each individual. Patients are able to use words in conversational speech that they cannot comprehend out of context in experimental tasks, and they retain bits of information about objects that are related to their personal lives (e.g., their own vase or furniture), while losing general knowledge about the same objects if they are unfamiliar and have no personal relevance (e.g., someone else's vase; Snowden, Griffiths, \& Neary, 1994, 1995, 1996, 1999). Furthermore, semantic dementia patients are able to recognize, identify, and match the names of personally relevant individuals better than those of celebrities and are better at identifying and localizing places they have visited than equally well-known places that they have not (Snowden et al., 1994, 1995; Westmacott, Leach, Freedman, \& Moscovitch, 2001). Moreover, Westmacott et al. (2001) recently documented a semantic dementia patient who showed greater familiarity with and more accurate pronunciation of famous names that were 
judged to be highly memorable and personally significant for people in his cohort and, presumably, for him as well.

If AS contributes to the content and organization of semantic memory, as the clinical evidence suggests, then in addition to its role in determining patterns of semantic breakdown following brain damage, AS should influence the performance of control participants on a variety of cognitive tasks, which should provide new insights into the structure of knowledge. To examine this hypothesis, we adapted the remember/know $(\mathrm{R} / \mathrm{K})$ paradigm, first introduced by Tulving (1989), and applied it to the assessment of memories previously acquired outside the laboratory. This contrasts with the usual application of the $\mathrm{R} / \mathrm{K}$ paradigm in the assessment of episodic memory for experimentally presented stimuli (for reviews, see Gardiner, Ramponi, \& Richardson-Klavehn, 2002, and Knowlton, 1998). We asked two large groups of control participants to make $\mathrm{R} / \mathrm{K}$ judgments about famous names from the 20 th century, just as has been done for words and pictures in episodic memory tasks. We instructed participants to give a remember $(\mathrm{R})$ response if they could recollect a particular episode involving or associated with the famous name. For example, someone would give an $\mathrm{R}$ response to the name John Lennon if he or she could recall a particular experience of watching him on television or in concert or the experience of hearing about his assassination. In contrast, participants were instructed to give a know $(\mathrm{K})$ response if the person were merely familiar and not associated with any particular episodic memories, even if they knew many facts about him or her. For example, someone would give a $\mathrm{K}$ response to the name John Lennon if he or she knew that he was a member of the Beatles, that he was married to Yoko Ono, and that he was assassinated in 1980 but had no specific personal memories involving or associated with him. In short, knowledge of John Lennon consists of both semantic $(\mathrm{K})$ and episodic $(\mathrm{R})$ representations.

On the basis of these norming data, we constructed two sets of experimental items for each of the two age groups; one set consisted of famous names that received $\mathrm{R}$ responses from at least $80 \%$ of the participants in the norming study (high-R items), and the other consisted of famous names that received relatively few $\mathrm{R}$ responses (low- $\mathrm{R}$ items). The assumption underlying this adapted $\mathrm{R} / \mathrm{K}$ task is that famous names receiving a high proportion of $\mathrm{R}$ responses are likely to evoke personal memories and, therefore, to be more personally relevant or emotionally significant to most people of a given generation, relative to names primarily receiving $\mathrm{K}$ responses. These sets of high-R and low- $R$ famous names were matched in terms of familiarity and length and were used in four experimental tasks: free recall, delayed recognition, fame judgment, and speeded reading. The literature on the self-reference effect (Craik et al., 1999; Klein \& Kihlstrom, 1986; Klein \& Loftus, 1988; Rogers, Kuiper, \& Kirker, 1977; Symons \& Johnson, 1997; Wells, Hoffman, \& Enzle, 1984) suggests that AS influences episodic memory processes. Thus, we predicted that participants would exhibit better performance for personally relevant famous names on two tests of episodic memory - free recall and delayed recognition.
Moreover, on the basis of evidence from semantic dementia that AS can contribute to the representation and retrieval of knowledge that is ostensibly semantic, we hypothesized that it may be easier to access or compute the representations of personally relevant semantic concepts because they include a rich network of contextual episodic associations that exist over and above abstract, generic semantic features. Because these autobiographically significant concepts can be accessed through both a semantic route and an episodic route, they may be computed faster during on-line experimental tasks. If this is the case, one also would expect participants to show better performance (i.e., shorter reaction times [RTs] and fewer errors) for personally relevant famous names on such tests as fame judgment and speeded reading, which are designed to tap the organization and structure of semantic representations. These hypotheses were examined in a group of healthy older adults (65-80 years) and a group of healthy middle-aged adults (45-55 years). The data from the older group are presented first. We included different age groups for two reasons: first, to increase the external validity of the finding s by showing that they are not limited to a specific population, and second, to obtain control data that could be used to interpret the performance of patients within these age ranges.

Confirmation of our hypotheses would have significant theoretical implications since, to our knowledge, no existing model of semantic memory addresses the possibility that autobiographical experience contributes directly to the long-term representation and structure of concept knowledge or even the weaker possibility that AS influences performance on tests of semantic memory. However, in some related work, McKoon and Ratcliff (1986), McKoon et al. (1986), and Ratcliff and McKoon (1986) presented evidence that episodic memory for newly learned word pairs contributes to performance on semantic memory tests and proposed a framework emphasizing the interaction and overlap between these two memory systems. Although episodic memories acquired in the context of an experiment are very different from real-life autobiographical memories, their findings are relevant to our experiments because they suggest that, during the performance of semantic memory tasks, information that is not semantically related to a target stimulus may be activated automatically. This suggests that there may be a constant interaction between episodic and semantic memory that is automatic and obligatory. In our experiments, we sought to investigate whether or not a similar interaction exists between autobiographical and semantic memory.

EXPERIMENT 1

Remember/Know Judgments of Famous Names

Experiment 1A Norms for 65- to 80-Year-Olds

\section{Method}

Participants. Fifty neurologically intact participants, 30 men and 20 women between the ages of 65 and 80 years $(M=71.7$ years), participated in the norming study; the participants had completed, 
on average, 12.2 years of education, and all had been living in Canada for at least 45 years.

Materials and Procedure. The stimulus set consisted of $196 \mathrm{fa}-$ mous names from across the 20th century. Names were restricted to individuals who were alive and famous during the lifetimes of the participants (i.e., 1940-present). Famous names were not chosen in order to obtain an equal distribution across all time periods, nor were the candidates for inclusion restricted to those whose fame was confined to a short period of time. Rather, famous individuals were chosen on the basis of their stature, their significance in 20th-century Western history, and most important, the likelihood that they would have had some personal impact upon individual citizens of this generation. As a result, the fame of several of the people spanned many years

The participants were presented with the set of 196 famous names and were asked to make an $\mathrm{R} / \mathrm{K}$ judgment for each. The participants were instructed to give an $\mathrm{R}$ response if they could reexperience a particular episode in which they watched, listened to, or heard about the famous person or if reading the person's name triggered some other specif ic personal memory. If the participants knew the identity of the famous person but could not recall a specific episode involving him or her, they were instructed to give a $\mathrm{K}$ response. The participants were also asked to rate the familiarity of each famous name (on the basis of the frequency with which the name is/was encountered; 7-point scale, where 1 = barely familiar and $7=$ extremely familiar ) and, for those names given $\mathrm{R}$ responses, to rate the vividness and strength of the elicited memory (7-point scale, where $1=$ very vague and $7=$ extremely detailed and vivid).

In order to examine whether or not AS-indicated by making an $\mathrm{R}$ judgment-is distinct from emotional significance, following the initial collection of norms, a separate group of 25 participants (12 men and 13 women; $M=72.5$ years old; $M=13.3$ years of education) was asked to rate the emotionality of each of the 196 famous names. The participants were instructed to indicate the degree to which each name was associated with a personal opinion and/or affective reaction (7-point scale, where $1=$ no emotional reaction or opinion and $7=$ extremely strong emotional reaction and/or opinion).

\section{Results}

For each famous name, four variables were calculated: percentage of control participants who gave it an $\mathrm{R}$ response ( percent $R$ ), mean rating for vividness of memory (weighted average calculated by including only those participants who gave $\mathrm{R}$ responses for that name), mean $\mathrm{fa}$ miliarity rating, and mean emotionality rating. Bivariate correlations between familiarity, percent R, vividness, and emotionality were calculated (Table 1). Familiarity was positively correlated with percent $\mathrm{R}$, emotionality, and vividness. Of note, the strongest correlation was between percent $\mathrm{R}$ and emotionality, followed by the correlation between vividness and recency. Moreover, percent $\mathrm{R}$ and vividness were more strongly correlated with emotionality than with familiarity. This suggests that familiarity and AS are distinct from one another and that they tap different dimensions of knowledge.

\section{Experiment 1B Norms for 45- to 55-Year-Olds}

\section{Method}

Participants. Fifty neurologically intact participants, 25 men and 25 women between the ages of 45 and 55 years old $(M=$ 50.4 years), participated in the norming study; participants had completed, on average, 15.2 years of education, and all had been living in Canada for at least 35 years.

Materials and Procedure. The stimulus set consisted of 236 famous names from across the 20th century. The same selection criteria as those used in Experiment 1A were used to construct the stimulus set, which was divided into the same four time periods, ${ }^{1}$ and which was validated by 10 control participants $(M=47.6$ years). The participants were presented with the set of 236 famous names and were asked, for each item, to make an $\mathrm{R} / \mathrm{K}$ judgment and to rate familiarity and memory vividness. The instructions and procedure were identical to those in Experiment 1A. As in Experiment 1A, following the initial collection of norms, a separate group of 25 participants $(M=48.5$ years $)$ was asked to rate the emotionality of each of the 236 famous names.

\section{Results}

As in Experiment 1A, percent R, vividness, familiarity, and emotionality were calculated for each famous name; their intercorrelations are presented in Table 1. Similar to the findings from the 65- to 80-year-old group, familiarity was significantly positively correlated with percent R, emotionality, and vividness. Percent R was more strongly correlated with emotionality than with familiarity. In addition, the strongest correlation was between percent $\mathrm{R}$ and emotionality.

\section{Discussion}

The results of these two norming studies suggest that it is meaningful to describe semantic memory in terms of the degree to which it is relevant to one's personal expe-

Table 1

Correlations Between Variables Included in Famous Names Norming Studies

\begin{tabular}{|c|c|c|c|c|c|c|}
\hline Characteristic & $\begin{array}{l}\text { Age Group } \\
\text { (Years) }\end{array}$ & Time & Familiarity & Percent $\mathrm{R}$ & Emotionality & Vividness \\
\hline \multirow[t]{2}{*}{ Time } & $65-80$ & 1 & & & & \\
\hline & $45-55$ & 1 & & & & \\
\hline \multirow[t]{2}{*}{ Familiarity } & $65-80$ & .081 & 1 & & & \\
\hline & $45-55$ & .022 & 1 & & & \\
\hline \multirow[t]{2}{*}{ Percent R } & $65-80$ & $.224 * *$ & $.296^{* *}$ & 1 & & \\
\hline & $45-55$ & $.312 * *$ & $.378^{* *}$ & 1 & & \\
\hline \multirow[t]{2}{*}{ Emotionality } & $65-80$ & $.324 * *$ & $.233 * *$ & $.737 * *$ & 1 & \\
\hline & $45-55$ & $.309 * *$ & $.422 * *$ & $.758 * *$ & 1 & \\
\hline \multirow[t]{2}{*}{ Vividness } & $65-80$ & $-.544 * *$ & $.274 * *$ & $.303 * *$ & $.374 * *$ & 1 \\
\hline & $45-55$ & $-.563 * *$ & $.313 * *$ & $.309 * *$ & $.473 * *$ & 1 \\
\hline
\end{tabular}

** Correlation is significant at the .01 level (two-tailed). 
rience. We found that some famous names were more likely than others to hold some personal significance for the participants. In both age groups, judgments of AS appeared to be partially independent of name familiarity but overlapped considerably with ratings of emotional salience. Thus, the present findings suggest that the $\mathrm{R} / \mathrm{K}$ paradigm can be adapted successfully for the study of memories acquired outside the laboratory and that it may provide a tool for investigating the relationship between autobiographical experience and semantic memory.

\section{EXPERIMENT 2 \\ The Influence of Autobiographical Significance on Experimental Task Performance}

There are reasons to predict that AS will influence performance on both episodic and semantic memory tests. Specifically, we expected that the participants would show better recall of high-R, relative to low-R, famous names presented in a single-trial list-learning task and higher rates of recognition when presented with these names after a delay. Moreover, we expected that the participants would be quicker to judge high-R names as famous and quicker to read high- $R$ names presented individually on a computer screen. These predictions were examined in participants from two age groups: $45-55$ years and $65-80$ years.

\section{Experiment 2A 65- to 80-Year-Olds}

\section{Method}

Participants. Sixteen right-handed participants, 8 men and 8 women between the ages of 65 and 80 years, participated in four experimental tasks. On average, the participants had completed 13.5 years of education, and all had been living in Canada for at least 45 years.

Materials and Experimental Tasks. The norming data from Experiment 1A were used to construct the stimulus set (Appendix A), consisting of 50 famous names-25 high-R names (names that had received $\mathrm{R}$ responses from at least $80 \%$ of the participants from the norming study) and 25 low-R names (names that had received $\mathrm{R}$ responses from fewer than $20 \%$ of the participants from the norming study). The high-R and the low-R sets differed significantly with respect to percent $R$ and vividness but were matched with respect to length (in letters) and familiarity (Table 2). It was not possible to match the two sets on emotionality; the names on the high-R list received signif icantly higher emotionality ratings than did the names on the low-R list (Table 2).

In order to rule out the possible confound between the likelihood of giving an R response and the amount of factual information possessed for a given famous name (i.e., degree of semantic elaboration), another group of 16 participants ( 8 men and 8 women) between the ages of 65 and 80 years $(M=71.8$ years), with an average of 12.9 years of education, was asked to list as many semantic features as they could for each of the $\mathbf{5 0}$ famous names from the stimulus set. A semantic feature was defined as a fact or piece of information about the famous person, such as occupation, age, nationality, name of spouse, number of children, name of a movie starred in, name of political affiliation, or a specific event in which the person was involved. Examples of possible semantic features for three famous individuals were provided, and the participants were encouraged to ask questions. The participants were discouraged from providing a lot of detail about the physical appearance of the person, except in cases in which a specific physical feature was considered to be integral to that individual's identity (e.g., Michael Jackson's changing skin color). Mean number of semantic features was calculated for each famous name. These scores were then averaged across all names in the high-R and low-R sets. No difference in number of semantic features listed was found between the high- $\mathrm{R}$ and the low-R sets (Table 2).

These stimuli were used in four experimental tasks (described below): free recall, delayed recognition, fame judgment, and speeded reading. The experimental session progressed as follows: free recall task, 15-min distractor task (speeded feature verification; e.g., "does a bird have wings?"), delayed recognition task, 30-min distractor task (speeded picture naming), fame judgment or speeded reading, 30-min distractor task (feature listing of common concepts; e.g., "tell me everything you can about a limousine"), and speeded reading or fame judgment. The fame judgment and speeded reading tasks were counterbalanced across participants.

Free recall task. The high-R and low-R sets each were divided into 5 lists of five names. Four buffer items were added to each list - two at the beginning and two at the end-resulting in 10 lists, each with 9 items. The 5 high-R lists were matched with respect to percent $\mathrm{R}$, vividness, familiarity, emotionality, and length, as were the 5 low-R lists. Buffer items were matched on all of these variables across all 10 lists.

The lists were read aloud by the experimenter, one at a time in random order, at a rate of approximately one name every $2 \mathrm{sec}$. Im-

Table 2

Characteristics of the High-R and Low-R Lists Used in Experiments 2A and 2B

\begin{tabular}{|c|c|c|c|}
\hline Characteristic & $\begin{array}{c}\text { High-R List } \\
(M)\end{array}$ & $\begin{array}{c}\text { Low-R List } \\
(M)\end{array}$ & $\begin{array}{r}\text { Significance } \\
(p, \text { two-tailed }\end{array}$ \\
\hline \multicolumn{4}{|c|}{ Experiment 2A: 65 - to 80 -Year-Olds } \\
\hline Percent R & $85.09 \%$ & $12.80 \%$ & $<.0001$ \\
\hline Vividness (maximum, 7) & 4.64 & 1.31 & $<.0001$ \\
\hline Emotionality (maximum, 7) & 5.31 & 1.74 & $<.0001$ \\
\hline Familiarity (maximum, 7) & 4.24 & 4.78 & .7012 \\
\hline No. semantic features & 6.78 & 7.23 & .4524 \\
\hline Length (letters) & 12.13 & 11.41 & .0836 \\
\hline \multicolumn{4}{|c|}{ Experiment 2B: 45 - to 55-Year-Olds } \\
\hline Percent R & $86.40 \%$ & $13.20 \%$ & $<.0001$ \\
\hline Vividness (maximum, 7) & 4.42 & 1.26 & $<.0001$ \\
\hline Emotionality (maximum, 7) & 4.72 & 1.70 & $<.0001$ \\
\hline Familiarity (maximum, 7) & 4.77 & 5.01 & .5000 \\
\hline No. semantic features & 6.73 & 7.49 & .1400 \\
\hline Length (letters) & 11.84 & 11.96 & .8500 \\
\hline
\end{tabular}


mediately after the list was presented, the participants were asked to recall as many names as possible, in any order. Order of recall was recorded by the experimenter. After five lists had been read and recalled, the participants engaged in a 7-min nonverbal distractor task to reduce the impact of proactive interference upon performance. The participants were not told that their memory for these names would be tested again in a later recognition task. The participants began with three practice trials using lists of country/city names and then completed the experimental trials.

Delayed recognition task. After engaging in a distractor task for $15 \mathrm{~min}$, the participants were presented with a list of 180 famous names-the 90 names from the free recall task and 90 new names. The participants were asked to identify which names had been read by the experimenter by circling them on the page. This task was untimed.

Fame judgment task. In addition to the 50 target stimuli (25 high-R and 25 low-R names), a set of 50 nonfamous distractor names was constructed. Target and distractor names were matched with respect to male/female ratio and length. Each trial proceeded as follows: a fixation cross in the center of the computer screen for $500 \mathrm{msec}$, a blank screen for $100 \mathrm{msec}$, and a name in the center of the screen for $5 \mathrm{sec}$ or until the participant responded. The trials were randomly ordered. The instructions were presented visually on the screen and also were read aloud by the experimenter. The participants were asked to read the name to themselves and to indicate, as quickly and accurately as possible, whether or not the name denoted a famous individual. The participants made their responses by pressing one of two keys on the keyboard; the yes/no mappings onto these two keys were counterbalanced across participants. The participants began with a practice session consisting of 26 trials (half famous, half nonfamous); following an opportunity to ask questions, the participants completed the 100 experimental trials. Decision latency, in milliseconds, defined as the period between the onset of the name and the onset of the participant's response, was recorded for each trial by the computer. Error rate was also recorded. No feedback was provided.

Speeded reading task. The 50 target and 50 distractor names from the fame judgment task were used in the speeded reading task. The procedure was identical to that for the previous task; however, instead of making a fame judgment about each name, the participants were asked to read each name aloud into a microphone as quickly and accurately as possible. The stimulus remained on the screen for $5 \mathrm{sec}$, or until the onset of the participant's voice. This discouraged the participants from sounding out names aloud; instead, it encouraged them to refrain from responding until a complete phonological representation of the name had been computed. The participants began with a practice session consisting of 26 trials (half famous, half nonfamous); following an opportunity to ask questions, the participants completed the 100 experimental trials. Voice onset time (VOT; in milliseconds) was recorded by the computer. Pronunciation errors were coded manually on the keyboard by the experimenter. No feedback was provided.

\section{Results}

Free recall task. For each participant, the percentage of target names recalled correctly was calculated across the five high-R lists and across the five low-R lists. These scores were averaged across participants to obtain the mean percentage of high- $\mathrm{R}$ and low-R names recalled correctly. The participants recalled significantly more names from the high-R lists $(M=65.8 \%, S D=$ 9.3\%) than from the low-R lists $[M=48.0 \%, S D=5.5 \%$; $t(15)=6.12, p<.0001]$.

Delayed recognition task. Two overall performance scores were calculated by subtracting the percentage of false recognitions from the percentage of correct recog- nitions separately for the high-R names and the low- $\mathrm{R}$ names. These performance scores were then averaged across participants. The participants recognized significantly more names from the high-R lists $(M=91.2 \%$, $S D=3.9 \%)$ than from the low-R lists $[M=80.8 \%, S D=$ $7.0 \% ; t(15)=5.18, p<.0001]$.

Fame judgment task. Mean RTs and standard deviations for high-R names and low-R names were calculated for each participant and then were averaged across all the participants. A repeated measures analysis of variance revealed significant differences in RT between high-R $(M=857.61 \mathrm{msec}, S D=123.98 \mathrm{msec})$, low-R $(M=$ $931.46 \mathrm{msec}, S D=135.58 \mathrm{msec})$, and nonfamous $(M=$ $1,231.02 \mathrm{msec}, S D=122.22 \mathrm{msec})$ names $[F(2,30)=$ $167.99, p<.0001]$. Planned comparisons indicated that, relative to nonfamous names, the participants responded significantly more quickly to both high- $\mathrm{R}[F(1,15)=$ $231.98, p<.0001]$ and low- $\mathrm{R}[F(1,15)=129.58, p<.0001]$ names. Moreover, they responded significantly more quickly to high-R names than to low-R names $[F(1,15)=$ $52.90, p<.0001]$. An analysis of variance performed on the error data revealed findings consistent with the RT data. There were significant differences in percentage of errors between high- $\mathrm{R}(M=0.25 \%, S D=1.00 \%)$, low-R $(M=1.75 \%, S D=2.52 \%)$, and nonfamous $(M=4.29 \%$, $S D=5.16 \%)$ names $[F(1,30)=5.44, p<.01]$. Planned comparisons indicated that the participants made significantly fewer errors on high-R names, relative to nonfamous names $[F(1,15)=10.00, p<.006]$, but that there was no significant difference in error rate between low- $R$ names and nonfamous names $[F(1,15)=2.48$, n.s.]. In addition, the participants made significantly fewer errors on high-R names, relative to low-R names $[F(1,15)=5.87$, $p<.03$ ].

In order to examine further the relationships between AS (i.e., percent R), vividness, familiarity, emotionality, amount of semantic knowledge, length, and RT in the fame judgment task, a correlational analysis was performed (Table 3). Vividness, percent R, emotionality, amount of semantic knowledge, and familiarity were all negatively correlated with RT, indicating that higher ratings on these variables were associated with shorter RTs. The correlation between length and RT was not significant. When the influence of emotionality was partialed out, RT remained significantly correlated with vividness, percent R, familiarity, and amount of semantic knowledge, and the correlation between RT and length became significant. These findings suggest that, despite the close relationship between emotionality and AS, each has a unique, independent influence on participants' performance on speeded fame judgment.

Speeded reading task. Mean VOTs and standard deviations for high-R names and low-R names were calculated for each participant and then averaged across all the participants. The pattern of results and their significance were similar to those obtained in the fame judgment task. A repeated measures analysis of variance revealed significant differences in VOT between high- $R$ 
Table 3

Performance in the Fame Judgment and Speeded Reading Tasks for 65- to 80-Year-Olds and 45- to 55-Year-Olds: Correlations (Pearson $r$ ) With Percent R, Vividness, Familiarity, Emotionality, Amount of Semantic Knowledge, Recency, and Length (With Correlation Coefficients After Emotionality Was Partialed Out in Parentheses)

\begin{tabular}{|c|c|c|c|c|}
\hline \multirow[b]{2}{*}{ Characteristic } & \multicolumn{2}{|c|}{$65-80$ Years } & \multicolumn{2}{|c|}{$45-55$ Years } \\
\hline & $\begin{array}{l}\text { Fame Judgment } \\
\text { (RT) }\end{array}$ & $\begin{array}{c}\text { Speeded Reading } \\
\text { (VOT) }\end{array}$ & $\begin{array}{l}\text { Fame Judgment } \\
\text { (RT) }\end{array}$ & $\begin{array}{c}\text { Speeded Reading } \\
\text { (VOT) }\end{array}$ \\
\hline Percent R & $\begin{array}{l}-.616 * * \\
(-.389)^{* *}\end{array}$ & $\begin{array}{l}-.422 * * \\
(-.415) * *\end{array}$ & $\begin{array}{l}-.614 * * \\
(-.463) * *\end{array}$ & $\begin{array}{l}-.504 * * \\
(-.446) * *\end{array}$ \\
\hline Vividness & $\begin{array}{l}-.647 * * \\
(-.432) * *\end{array}$ & $\begin{array}{l}-.401 * * \\
(-.442)^{* *}\end{array}$ & $\begin{array}{l}-.657 * * \\
(-.518) * *\end{array}$ & $\begin{array}{l}-.562 * * \\
(-.554) * *\end{array}$ \\
\hline Familiarity & $\begin{array}{l}-.283^{*} \\
(-.362)^{* *}\end{array}$ & $\begin{array}{l}-.276^{*} \\
(-.378)^{* *}\end{array}$ & $\begin{array}{l}-.335 * * \\
(-.379) * *\end{array}$ & $\begin{array}{l}-.338 * * \\
(-.366) * *\end{array}$ \\
\hline Emotionality & $-.544 * *$ & $-.340^{* *}$ & $-.397 * *$ & $-.309 *$ \\
\hline Semantic & $\begin{array}{l}-.379 * * \\
(-.296) *\end{array}$ & $\begin{array}{l}-.304 * \\
(-.288)^{*}\end{array}$ & $\begin{array}{l}-.341 * * \\
(-.186)\end{array}$ & $\begin{array}{l}-.329 * \\
(-.210)\end{array}$ \\
\hline Recency & $\begin{array}{l}-.344 * * \\
(-.262)\end{array}$ & $\begin{array}{l}-.376^{* * *} \\
(-.242)\end{array}$ & $\begin{array}{l}-.089 \\
(-.069)\end{array}$ & $\begin{array}{l}-.097 \\
(-.081)\end{array}$ \\
\hline Length & $\begin{array}{l}.265 \\
(.346)^{*}\end{array}$ & $\begin{array}{l}.391 * * \\
(.415)^{* *}\end{array}$ & $\begin{array}{l}.359 * * \\
(.408)^{* *}\end{array}$ & $\begin{array}{l}.521 * * \\
(.560)^{* *}\end{array}$ \\
\hline
\end{tabular}

*Correlation is significant at the .05 level (two-tailed). $* *$ Correlation is significant at the .01 level (two-tailed).

$(M=691.71 \mathrm{msec}, S D=76.70 \mathrm{msec})$, low-R $(M=$ $763.04 \mathrm{msec}, S D=82.03 \mathrm{msec})$, and nonfamous $(M=$ $1,068.56 \mathrm{msec}, S D=138.96 \mathrm{msec})$ names $[F(2,30)=$ $99.95, p<.0001]$. Relative to nonfamous names, the participants responded significantly more quickly for both high- $\mathrm{R}[F(1,15)=121.79, p<.0001]$ and low- $\mathrm{R}[F(1,15)=$ $79.65, p<.0001]$ names. Moreover, they responded significantly more quickly to high-R names than to low-R names $[F(1,15)=75.19, p<.0001]$. Similarly, an analysis of the error data revealed significant differences in percentage of errors between high-R $(M=0.25 \%, S D=$ $1.00 \%)$, low-R $(M=0.75 \%, S D=1.61 \%)$, and nonfamous $(M=8.75 \%, S D=5.88 \%)$ names $[F(1,30)=31.26, p<$ $.0001]$. Relative to nonfamous names, the participants made significantly fewer errors on both high-R names $[F(1,15)=39.05, p<.0001]$ and low-R names $[F(1,15)=$ $28.24, p<.0001]$. However, the high- $\mathrm{R}$ and the low-R names did not differ significantly with respect to percentage of pronunciation errors $[F(1,15)=1.00$, n.s. $]$.

Correlations were calculated between VOT and the seven predictor variables. The findings were largely consistent with those from the fame judgment task, although VOT was also significantly correlated with length (Table 3).

\section{Experiment 2B 45- to 55-Year-Olds}

\section{Method}

Participants. Sixteen right-handed participants, 8 men and 8 women between the ages of 45 and 55 years, participated in four experimental tasks. On average, the participants had completed 14.9 years of education, and all had been living in Canada for at least 35 years.

Materials and Experimental Tasks. The norming data from Experiment 1B were used to construct the stimulus set (Appendix $\mathrm{B}$ ), consisting of 50 famous names-25 high-R names (names that had received $\mathrm{R}$ responses from at least $80 \%$ of the participants in the norming study) and 25 low-R names (names that had received
$\mathrm{R}$ responses from fewer than $20 \%$ of the participants in the norming study). In all other respects, Experiment 2B was identical to Experiment $2 \mathrm{~A}$ (see Table 2 for statistical comparison of the high-R and the low-R sets).

\section{Results}

Free recall task. The participants recalled significantly more names from the high-R lists $(M=75.0 \%$, $S D=7.0 \%)$ than from the low-R lists $[M=63.2 \%, S D=$ $7.4 \% ; t(15)=7.70, p<.0001]$.

Delayed recognition task. The participants recognized significantly more names from the high-R lists $(M=92.25 \%, S D=5.6 \%)$ than from the low-R lists $[M=$ $82.4 \%, S D=5.2 \% ; t(15)=6.16, p<.0001]$.

Fame judgment task. Mean RTs and standard deviations for high-R names and low-R names were calculated for each participant and then averaged across all the participants. There were significant differences in RT among high-R $(M=820.23 \mathrm{msec}, S D=88.01 \mathrm{msec})$, low- $\mathrm{R}(M=$ $883.99 \mathrm{msec}, S D=100.74 \mathrm{msec})$, and nonfamous $(M=$ $1,201.28 \mathrm{msec}, S D=161.05 \mathrm{msec})$ names $[F(2,30)=$ $88.68, p<.0001]$. Relative to nonfamous names, the participants responded significantly more quickly to both high- $\mathrm{R}[F(1,15)=124.80, p<.0001]$ and low- $\mathrm{R}[F(1,15)=$ $74.98, p<.0001]$ names. Moreover, they responded significantly more quickly to high-R names than to low-R names $[F(1,15)=13.02, p<.003]$. In addition, there were significant differences in percentage of errors among high-R $(M=1.25 \%, S D=1.91 \%)$, low-R $(M=2.00 \%$, $S D=2.07 \%)$, and nonfamous $(M=4.25 \% ; S D=3.71 \%)$ names $[F(1,30)=4.80, p<.02]$. Relative to nonfamous names, the participants made significantly fewer errors on both high-R names $[F(1,15)=8.42, p<.02]$ and low-R names $[F(1,15)=6.43, p<.05]$. There was no significant difference in error rate between the high-R and the low-R names $[F(1,15)=1.31$, n.s.]. The correlational analyses were consistent with the data for the 65- to 
80-year-olds, although recency was not significantly correlated with RT (see Table 3).

Speeded reading task. Mean VOTs and standard deviations for high-R names and low-R names were calculated for each participant and then averaged across all the participants. There were significant differences in VOT among high-R $(M=656.95 \mathrm{msec}, S D=46.45 \mathrm{msec})$, low-R $(M=714.73 \mathrm{msec}, S D=46.04 \mathrm{msec})$, and nonfamous $(M=1,001.26 \mathrm{msec}, S D=75.39 \mathrm{msec})$ names $[F(2,30)=393.51, p<.0001]$. Relative to nonfamous names, the participants read both high-R $[F(1,15)=$ 443.91, $p<.0001]$ and low-R $[F(1,15)=527.96, p<$ $.0001]$ names significantly more quickly. Moreover, the participants responded significantly more quickly to high-R names than to low-R names $[F(1,15)=34.85, p<$ $.0001]$. An analysis of the error data revealed significant differences in percentage of errors between high-R $(M=$ $0.75 \%, S D=1.61 \%)$, low-R $(M=1.00 \%, S D=1.79 \%)$, and nonfamous $(M=6.00 \%, S D=3.58 \%)$ names $[F(1,30)=25.16, p<.0001]$. Relative to nonfamous names, the participants made significantly fewer errors on both high-R names $[F(1,15)=28.85, p<.0001]$ and low-R names $[F(1,15)=26.78, p<.0001]$. However, the high-R and the low-R names did not differ significantly with respect to percentage of pronunciation errors $[F(1,15)=0.32$, n.s. $]$. The correlational analyses were consistent with the data from the fame judgment task (see Table 3).

Replication of fame judgment and speeded reading tasks. It is possible that performance on the two speeded tasks (fame judgment and speeded reading) from Experiment 2 may have been contaminated by previous exposure to the experimental stimuli. Repeated exposure to the names could increase the likelihood of finding an influence of AS on task performance if the effect from earlier tasks carried over into later performance. Conversely, it is also conceivable that previous exposure to the names could decrease the likelihood of finding such an effect through practice effects. In order to examine these possible confounds, two separate groups of participants performed the fame judgment and speeded reading tasks without having completed the recall and recognition tasks.

A group of 8 right-handed participants (4 men and 4 women) between the ages of 65 and 80 years $(M=$ 70.5 years), with an average of 13.3 years of education, and a group of 8 right-handed participants ( 4 men and 4 women) between the ages of 45 and 55 years $(M=50.2$ years), with an average of 14.1 years of education, took part in the replication experiments. The data were entirely consistent with those from the initial study.

An analysis of the 65- to 80-year-old group's data revealed significant differences in RT between high-R $(M=1,000.62 \mathrm{msec}, S D=66.71 \mathrm{msec})$, low-R $(M=$ $1,069.15 \mathrm{msec}, S D=64.93 \mathrm{msec})$, and nonfamous $(M=$ $1,338.66 \mathrm{msec}, S D=87.89 \mathrm{msec})$ names $[F(2,14)=$ $209.47, p<.0001]$. Relative to nonfamous names, the participants were significantly quicker to respond to both high- $\mathrm{R}[F(1,7)=373.35, p<.0001]$ and low- $\mathrm{R}$ $[F(1,7)=133.41, p<.0001]$ names. Moreover, they responded significantly more quickly to high-R names than to low-R names $[F(1,7)=73.15, p<.0001]$. Similarly, significant differences in VOT were found between high-R $(M=815.95 \mathrm{msec}, S D=38.89 \mathrm{msec})$, low-R $(M=858.93 \mathrm{msec}, S D=48.75 \mathrm{msec})$, and nonfamous $(M=1,033.35 \mathrm{msec}, S D=67.99 \mathrm{msec})$ names $[F(2,14)=$ $78.79, p<.0001]$ in the speeded reading task. Relative to nonfamous names, the participants were significantly quicker at reading both high- $\mathrm{R}[F(1,7)=89.45, p<$ $.0001]$ and low-R $[F(1,7)=68.41, p<.0001]$ names. Moreover, they responded significantly more quickly to high-R names than to low- $\mathrm{R}$ names $[F(1,7)=50.90, p<$ $.0001]$. Error data from the two tasks were consistent with those from the initial study.

Similar results were found for the 45- to 55-year-old group. There were significant differences in RT between high-R $(M=898.38 \mathrm{msec}, S D=40.83 \mathrm{msec})$, low- $\mathrm{R}$ $(M=940.76 \mathrm{msec}, S D=50.26 \mathrm{msec})$, and nonfamous $(M=1,135.30 \mathrm{msec}, S D=56.85 \mathrm{msec})$ names $[F(2,14)=$ $110.47, p<.0001]$ on the fame judgment task. Relative to nonfamous names, the participants were significantly quicker at responding to both high- $\mathrm{R}[F(1,7)=136.63$, $p<.0001]$ and low- $\mathrm{R}[F(1,7)=126.17, p<.0001]$ names. They were also significantly quicker at responding to high-R names than to low- $\mathrm{R}$ names $[F(1,7)=11.50, p<$ $.02]$. On the speeded reading task, there were significant differences in VOT between high- $\mathrm{R}(M=754.06 \mathrm{msec}$, $S D=45.21 \mathrm{msec})$, low-R $(M=791.85 \mathrm{msec}, S D=$ $49.99 \mathrm{msec})$, and nonfamous $(M=958.87 \mathrm{msec}, S D=$ $47.93 \mathrm{msec})$ names $[F(2,14)=183.48, p<.0001]$. Relative to nonfamous names, the participants were significantly quicker at reading both high- $\mathrm{R}[F(1,7)=253.68$, $p<.0001]$ and low-R $[F(1,7)=210.06, p<.0001]$ names, and they were significantly quicker at responding to high-R names than to low-R names $[F(1,7)=15.82$, $p<.005]$. Again, error data were consistent with those from the initial study.

\section{Discussion}

Across all four tasks, the participants from both age groups demonstrated a significant performance advantage for names judged to be autobiographically significant by a large group of age-matched peers. Famous names associated with specific personal memories were more likely to be recalled and recognized, consistent with other evidence about the effects of personal relevance on episodic memory (e.g., Craik et al., 1999; Klein \& Kihlstrom, 1986; Klein \& Loftus, 1988; Rogers et al., 1977; Symons \& Johnson, 1997; Wells et al., 1984). What is novel and more interesting is that AS also had a profound effect on tests of semantic memory: High-R names were judged as famous more quickly and were read out loud more quickly, relative to equally familiar famous names with no autobiographical associations. Moreover, percent $\mathrm{R}$ was more strongly correlated with RT and VOT, relative to other variables known to influ- 
ence semantic memory, such as familiarity ratings, number of semantic features listed, emotionality ratings, recency, and name length. Although the correlation analyses suggest that AS is closely linked to emotionality, the performance advantage for personally relevant names cannot be attributed solely to their emotional salience, because the advantage was still present in both groups after the influence of emotionality was partialed out.

\section{EXPERIMENT 3 \\ Classification of Famous Names According to Each Participant's Own R/K Judgments}

Although we were able to identify a group of famous names that received many $\mathrm{R}$ responses and a group that received very few, it is important to note that there was some variability across participants. Thus, it is possible that the high-R/low-R classifications used in Experiment 2 were not appropriate for every participant. That is, a given participant might not have had any autobiographical associations for some of the high-R names or, conversely, might have had autobiographical associations for some of the low-R names. In order to rule out this confound, two separate groups of participants were asked to make $\mathrm{R} / \mathrm{K}$ judgments for the 50 famous names after completing the four experimental tasks. Because the participants completed the experimental tasks and the $\mathrm{R} / \mathrm{K}$ task, performance could be evaluated by categorizing the stimuli into $R$ names and $K$ names on the basis of the participant's own responses.

\section{Experiment 3A 65- to 80-Year-Olds}

\section{Method}

Participants. A separate group of 16 participants $(7$ men and 9 women) between the ages of 65 and 80 years $(M=69.6$ years), with an average of 13.0 years of education, performed the recall, recognition, fame judgment, speeded reading, and R/K tasks.

Materials and Procedure. The materials and procedure were identical to those in the original experiment (Experiment 2A). After completing the four experimental tasks, the participants were asked to make $\mathrm{R} / \mathrm{K}$ judgments for each of the 50 names that had been used. For items given $\mathrm{R}$ responses, the participants were asked to rate the vividness of the associated memory on a scale from 1 to 7 $(1=$ vague with few details $; 7=$ extremely vivid with many contextual details). In addition, the participants were asked to rate each name with respect to familiarity, emotional salience, and amount of semantic knowledge.

\section{Results}

The R/K judgments made by the participants in the present study were highly consistent with those made by the participants in the norming study. Of the 25 names originally classified as high R, 22 were given R responses by at least 14 of the 16 participants. The remaining 3 names were given $R$ responses by 12,12 , and 13 participants, respectively. Of the 25 names originally classified as low R, 21 were given $\mathrm{K}$ responses by at least 14 of the 16 participants. The remaining 4 names were given $\mathrm{K}$ responses by $10,10,11$, and 13 participants, respectively. For each participant, the 50 famous names were classified according to his or her own $\mathrm{R} / \mathrm{K}$ judgments. These classifications were used for all the data analyses.

Free recall task. For each participant, the percentage of $\mathrm{R}$ names recalled correctly and the percentage of $\mathrm{K}$ names recalled correctly were calculated across the 10 lists. These scores were averaged across participants to obtain the mean percentages of $\mathrm{R}$ names and $\mathrm{K}$ names recalled correctly. The participants recalled significantly more R names $(M=71.2 \%, S D=0.07 \%)$ than $\mathrm{K}$ names $[M=49.9 \%, S D=0.08 \% ; t(15)=7.86, p<.0001]$.

Delayed recognition task. For each participant, two overall performance scores were calculated by subtracting the percentage of false recognitions from the percentage of correct recognitions separately for the $\mathrm{R}$ names and the $\mathrm{K}$ names. These performance scores were then averaged across participants. The participants recognized significantly more names from the high-R lists $(M=93.9 \%, S D=0.05 \%)$ than from the low-R lists $[M=$ $73.9 \%, S D=0.05 \% ; t(15)=6.80, p<.0001]$.

Fame judgment task. Mean RTs and standard deviations for high-R and low-R names were calculated for each participant and then were averaged across all the participants. A repeated measures analysis of variance revealed significant differences in RT between high-R $(M=845.09 \mathrm{msec}, S D=84.58 \mathrm{msec})$, low-R $(M=$ $943.98 \mathrm{msec}, S D=94.72 \mathrm{msec})$, and nonfamous $(M=$ $1,184.02 \mathrm{msec}, S D=115.82 \mathrm{msec})$ names $[F(2,30)=$ $90.11, p<.0001]$. Relative to nonfamous names, participants responded significantly more quickly to both high-R $[F(1,15)=127.02, p<.0001]$ and low- $\mathrm{R}[F(1,15)=$ $74.56, p<.0001]$ names. Moreover, they responded significantly more quickly to high-R names than to low-R names $[F(1,15)=17.20, p<.001]$. An analysis of variance performed on the error data revealed significant differences in percentage of errors between high- $\mathrm{R}(M=$ $1.03 \%, S D=0.003 \%)$, low-R $(M=1.35 \%, S D=0.006 \%)$, and nonfamous $(M=4.31 \%, S D=0.01 \%)$ names $[F(1,30)=4.94, p<.02]$. Relative to nonfamous names, the participants made significantly fewer errors on both high-R names $[F(1,15)=8.64, p<.02]$ and low-R names $[F(1,15)=7.02, p<.05]$. There was no significant difference in error rate between the high- $\mathrm{R}$ and the low- $\mathrm{R}$ names $[F(1,15)=1.16$, n.s. $]$.

Speeded reading task. Mean VOTs and standard deviations for high-R names and low-R names were calculated for each participant and then were averaged across all the participants. A repeated measures analysis of variance revealed significant differences in VOT between high-R $(M=683.25 \mathrm{msec}, S D=57.33 \mathrm{msec})$, low-R $(M=741.5 \mathrm{msec}, S D=51.28 \mathrm{msec})$, and nonfamous $(M=1,006.74 \mathrm{msec}, S D=92.15 \mathrm{msec})$ names $[F(2,30)=399.11, p<.0001]$. Relative to nonfamous names, the participants responded significantly more quickly to both high-R $[F(1,15)=451.53, p<.0001]$ and 
low- $\mathrm{R}[F(1,15)=530.29, p<.0001]$ names. Moreover, they were significantly quicker at responding to high-R names than to low-R names $[F(1,15)=39.26, p<.0001]$. Similarly, an analysis of the error data revealed significant differences in percentage of errors between high-R $(M=0.63 \%, S D=0.001 \%)$, low-R $(M=0.74 \%, S D=$ $0.001 \%)$, and nonfamous $(M=4.15 \%, S D=0.01 \%)$ names $[F(1,30)=22.06, p<.0001]$. Relative to nonfamous names, the participants made significantly fewer errors on both high-R names $[F(1,15)=21.33, p<$ $.0001]$ and low-R names $[F(1,15)=21.87, p<.0001]$. However, the high-R and the low-R names did not differ significantly with respect to percentage of pronunciation errors $[F(1,15)=0.19$, n.s. $]$.

\section{Experiment 3B 45- to 55-Year-Olds}

\section{Method}

Participants. A separate group of 16 participants (6 men and 10 women) between the ages of 45 and 55 years ( $M=48.9$ years), with an average of 14.8 years of education, performed the recall, recognition, fame judgment, speeded reading, and R/K tasks.

Materials and Procedure. The materials from Experiment $2 \mathrm{~B}$ were used, and the procedure was identical to that in Experiment $3 \mathrm{~A}$.

\section{Results}

As in Experiment 3A, the participants' $\mathrm{R} / \mathrm{K}$ judgments were highly consistent with the results of the norming study. Of the 25 names originally classified as high R, 23 were given $\mathrm{R}$ responses by at least 14 of the 16 participants. Each of the remaining 2 names was given an $\mathrm{R}$ response by 12 participants. Of the 25 names originally classified as low R, 20 were given $\mathrm{K}$ responses by at least 14 of the 16 participants. One of the names remaining received $12 \mathrm{~K}$ responses, and the other 4 each received $13 \mathrm{~K}$ responses. For each participant, the 50 famous names were classified according to his or her own $\mathrm{R} / \mathrm{K}$ judgments. These classifications were used for all the data analyses.

Free recall task. For each participant, the percentage of $\mathrm{R}$ names recalled correctly and the percentage of $\mathrm{K}$ names recalled correctly were calculated across the 10 lists. These scores were averaged across participants to obtain the mean percentage of $\mathrm{R}$ names and $\mathrm{K}$ names recalled correctly. The participants recalled significantly more R names $(M=77.9 \%, S D=0.03 \%)$ than $\mathrm{K}$ names $[M=62.09 \%, S D=0.04 \% ; t(15)=6.28, p<.0001]$.

Delayed recognition task. For each participant, two overall performance scores were calculated by subtracting the percentage of false recognitions from the percentage of correct recognitions separately for the $\mathrm{R}$ names and the $\mathrm{K}$ names. These performance scores were then averaged across participants. The participants recognized significantly more names from the high-R lists $(M=95.3 \%, S D=0.05 \%)$ than from the low-R lists $[M=$ $80.9 \%, S D=0.03 \% ; t(15)=6.24, p<.0001]$.

Fame judgment task. Mean RTs and standard deviations for high-R names and low-R names were calculated for each participant and then were averaged across all the participants. A repeated measures analysis of variance revealed significant differences in RT between high-R $(M=784.32 \mathrm{msec}, S D=68.48 \mathrm{msec})$, low- $\mathrm{R}(M=$ $852.06 \mathrm{msec}, S D=63.24 \mathrm{msec})$, and nonfamous $(M=$ $1,003.66 \mathrm{msec}, S D=138.48 \mathrm{msec})$ names $[F(2,30)=$ $86.03, p<.0001]$. Relative to nonfamous names, the participants were significantly quicker at responding to both high-R $[F(1,15)=118.55, p<.0001]$ and low-R $[F(1,15)=71.11, p<.0001]$ names. Moreover, they responded more quickly to high-R names than to low- $R$ names $[F(1,15)=16.86, p<.002]$. An analysis of variance performed on the error data revealed significant differences in percentage of errors between high- $\mathrm{R}(M=$ $0.86 \%, S D=0.002 \%)$, low-R $(M=0.97 \%, S D=0.002 \%)$, and nonfamous $(M=2.76 \%, S D=0.01 \%)$ names $[F(1,30)=4.55, p<.03]$. Relative to nonfamous names, the participants made significantly fewer errors on both high-R names $[F(1,15)=8.12, p<.03]$ and low-R names $[F(1,15)=6.97, p<.05]$. There was no significant difference in error rate between the high-R and the low-R names $[F(1,15)=1.08$, n.s. $]$.

Speeded reading task. Mean VOTs and standard deviations for high-R names and low-R names were calculated for each participant and then were averaged across all the participants. A repeated measures analysis of variance revealed significant differences in VOT between high-R $(M=658.44 \mathrm{msec}, S D=57.08 \mathrm{msec})$, low-R $(M=692.17 \mathrm{msec}, S D=52.61 \mathrm{msec})$, and nonfamous $(M=886.07 \mathrm{msec}, S D=85.48 \mathrm{msec})$ names $[F(2,30)=284.64, p<.0001]$. Relative to nonfamous names, the participants were significantly quicker at reading both high- $\mathrm{R}[F(1,15)=378.66, p<.0001]$ and low-R $[F(1,15)=410.50, p<.0001]$ names. Moreover, they responded more quickly to high-R names than to low-R names $[F(1,15)=36.44, p<.0001]$. Similarly, analysis of the error data revealed significant differences in percentage of errors between high- $\mathrm{R}(M=0.43 \%$, $S D=0.001 \%)$, low-R $(M=0.55 \%, S D=0.001 \%)$, and nonfamous $(M=2.84 \%, S D=0.008 \%)$ names $[F(1,30)=$ $18.28, p<.001]$. Relative to nonfamous names, the participants made significantly fewer errors on both high- $\mathrm{R}$ names $[F(1,15)=17.65, p<.001]$ and low-R names $[F(1,15)=17.04, p<.001]$. The high-R and the low-R names did not differ significantly with respect to percentage of pronunciation errors $[F(1,15)=0.11, \mathrm{n} . \mathrm{s}$.].

\section{Discussion}

The results of Experiment 3 indicate that performance based on each individual's classification of the AS of famous names corresponds closely to performance based on population ratings. The importance of this finding is that it provides a justification for developing a procedure to obtain objective norms that can be applied to an individual's autobiographical memory. Because autobiographical memory is inherently private, psychologists have relied on individualized assessment techniques. These results indicate that, although the content of the autobiographical ex- 
perience may be idiosyncratic, its association with selected public figures is not. Moreover, the differential effects that AS has on a variety of nonautobiographicalmemory tests indicate that one can test for the influence (or existence) of autobiographical memory without asking the individual to report that memory. This feature is particularly important for the study of individual differences in autobiographical memory in clinical populations where obtaining detailed interviews about autobiographical memory is not always possible and may not always be reliable or verifiable.

\section{GENERAL DISCUSSION}

We have argued that some semantic concepts are more likely than others to be associated with episodic memories of specific personal experiences and that this AS gives them a distinct status in long-term memory. We have presented experimental evidence of this distinct status in participants' superior performance on tests of episodic and semantic memory for famous names judged to be autobiographically significant by a large group of age-matched peers. Furthermore, when famous names were reclassified according to each participant's own $\mathrm{R} / \mathrm{K}$ judgments, this performance advantage for autobiographically significant names remained evident. Moreover, our findings suggest that AS can be distinguished from familiarity and generic factual knowledge about a given concept and that it is closely related to that concept's emotional salience, yet still distinct from it.

\section{Autobiographically Significant Knowledge: Semantic or Episodic?}

We have argued that autobiographically significant semantic concepts are associated with a distinct temporalspatial context, emotional salience, and/or a wealth of personalized or idiosyncratic information, in addition to abstract semantic facts. As a result, these concepts assume a distinct status in long-term memory that leads to enhanced performance advantage on experimental tasks. However, it is unclear whether the "extra," autobiographically significant information associated with these concepts is truly semantic in nature. According to our definition of AS and to traditional ideas about semantic and episodic memory (Tulving, 1972, 1983), it may be more appropriate to think of these personally relevant aspects of semantic concepts as episodic memories, not semantic ones.

This distinction between concept knowledge that is truly semantic and concept knowledge that is more episodic and contextual has been debated in the neuropsychological literature in regard to patterns of memory loss in semantic dementia (Graham, Lambon Ralph, \& Hodges, 1999; Snowden et al., 1999). Snowden et al. (1996) argued that personally relevant semantic concepts are more likely to remain intact in semantic dementia patients, relative to semantic concepts that have no special personal significance. As was discussed earlier, there is evidence that semantic dementia patients show a prefer- ential sparing of information about personally known individuals relative to celebrities, information about visited places relative to unvisited places, and information about autobiographically significant famous people relative to equally famous people with no personal associations (Snowden et al., 1994, 1995, 1996; Westmacott et al., 2001). However, although personally relevant semantic concepts may be more likely to remain accessible to patients, it should not be assumed that these knowledge representations are completely intact and comparable to those of a healthy control subject. Rather, semantic concepts that remain intact in semantic dementia typically become narrow, context specific, and highly personalized, so that only some aspects of concept meaning are retained. On the basis of these observations, Graham et al. (1999) argued that much of the knowledge that is preserved in semantic dementia lacks the defining qualities of semantic memory: It is not shared among individuals within a given society; it is not generalizable across situations and exemplars; and it is not abstract and noncontextual in nature. For example, Graham, Lambon Ralph, and Hodges (1997, 1999) described a semantic dementia patient whose only knowledge of the word clothes-peg was that it is used to clip cereal packages closed. Another patient was able to recognize and use her own kettle, but not a similar, although unfamiliar, kettle (Snowden et al., 1999).

This autobiographically constrained knowledge that appears to be spared preferentially in semantic dementia has much in common with the personally relevant aspects of famous person knowledge exhibited by the participants in the present study. Thus, we agree with Graham et al.'s (1999) suggestion that the contextually bound, personally specific knowledge demonstrated in semantic dementia patients is more episodic than semantic in nature, and we extend their ideas by showing how such knowledge contributes to "normal" conceptual representations in healthy individuals. We suggest that conceptual knowledge of people, objects, living things, places, encyclopedic facts, and abstract entities consists of a generic, noncontextual semantic component and, for some concepts, an additional, personally relevant, contextual episodic component. These two components exist independently, and each makes a unique contribution to knowledge representations. Furthermore, they may become dissociated in patients with brain damage (see Westmacott, Black, Freedman, \& Moscovitch, 2003). For the healthy individual in everyday circumstances, however, the semantic and episodic components of knowledge, although independent, are also interrelated, creating a rich, coherent conceptual representation that is partly generic (i.e., common across individuals) and partly specific (i.e., autobiographically constrained). ${ }^{2}$

Our findings raise many questions about the influence of autobiographicalexperience on the representation of semantic concepts. Further research is needed to clarify the distinction between episodic and semantic contributions to knowledge and to examine the relationships between AS, 
emotionality, and recency. Moreover, future studies should refine the remote memory version of the $\mathrm{R} / \mathrm{K}$ task and develop new paradigms to explore these questions.

\section{Implications for Models of Semantic Memory and Concept Knowledge}

Our findings also raise questions about the fundamental structure and organization of semantic memory and concept knowledge. Unlike previous studies in which the R/K paradigm was used (Eldridge, Knowlton, Furmanski, Bookheimer, \& Engel, 2000; Henson, Rugg, Shallice, Josephs, \& Dolan, 1999; Knowlton, 1998; Knowlton \& Squire, 1995; Tulving, 1989), we did not establish AS in the laboratory by asking participants to encode information in the context of the self or by asking participants to make $\mathrm{R} / \mathrm{K}$ judgments for words presented earlier in the experiment. Rather, in the present study, the degree to which concepts were autobiographically significant had been established already-incidentally, through real-world experience. The participants who participated in the behavioral experiments were required to perform only rudimentary analyses on the famous names to perform the tasks and were told nothing about AS or the R/K distinction. Given this, our finding of a performance advantage for high- $\mathrm{R}$ famous names not only suggests that AS influences on-line processes involved in the encoding, manipulation, and retrieval of information, but also raises the question as to whether it makes a contribution to the fundamental representation and structure of concept knowledge as well.

The terms knowledge and semantics often are used interchangeably to refer to abstract, generic, factual information that is represented independently of temporalspatial context. Accordingly, theoretical models of concept knowledge typically have highlighted the importance of semantic features in the representation of individual concepts and in the associative and hierarchical relationships among concepts and categories (e.g., Collins \& Loftus, 1975; Collins \& Quillian, 1969; McRae, de Sa, \& Seidenberg, 1997; Rosch, 1975; Rosch \& Mervis, 1975; Smith, Shoben, \& Rips, 1974; Warrington $\&$ Shallice, 1984). One prominent class of theories argues that through gradual repeated experience, we learn which features define and/or typify a particular concept, as well as the degree to which individual exemplars can vary in their featural composition and still be classified as a member of that concept (e.g., Billman \& Heit, 1988; Billman \& Knutson, 1996; Clapper \& Bower, 1991; Masson, 1995; McRae, Cree, Westmacott, \& de Sa, 1999; McRae et al., 1997; Seidenberg \& McClelland, 1989). Over time, patterns and regularities in the co-occurrence or clustering of semantic features are extracted, forming the basis for the structural organization of individual concepts and categories, as well as their interrelationships. Although there is general consensus that concept and category learning involves the abstraction of generic representations, there is considerable disagreement re- garding the degree to which information about individual exemplars remains available and whether such information is actually part of the core representation or whether it is accessed separately through subsequent processing (Estes, 1994; Medin \& Schaffer, 1978; Rips, 1989; Rosch, 1975, 1978). Regardless of whether prototype- or exemplar-based knowledge representations are favored, however, all of these theories focus exclusively on semantic features that have been abstracted from the episodic, personal context in which the concept was encountered. This contextual, personal information either is lost (McClelland, McNaughton, \& O'Reilly, 1995) or is retained separately from semantic knowledge as part of autobiographical episodic memory (Nadel \& Moscovitch, 1997).

In departure from traditional models of memory, we have argued that some knowledge that typically is classified as semantic has a contextual and episodic component. Furthermore, we argue that autobiographicallysignificant knowledge is distinguishable from autobiographical episodic memory - albeit subtly — because the former contributes directly to "semantic" concepts at the level of the representation, not simply to the processes involved in the acquisition and application of conceptual information. Last, this AS component is mediated by the hippocampus and perhaps by related structures in the medial temporal lobes and can be dissociated from the more conceptual semantic component (Westmacott et al., 2003).

The possibility that episodic information informs semantic memory in the way we describe has not been addressed in the cognitive literature and cannot be accommodated by current models of memory. Granted, most of the theories to which we refer were designed primarily to explain the way in which knowledge denoted by common nouns, such as objects and animals, is represented. As such, most theories focus on generic information, such as basic level representations. Even when dealing with subordinate level representations, the theories are concerned with exemplars as a type-for example, a certain kind of dog or car-not with a particular instance of it, and certainly not with the autobiographical context in which it was encountered. Insofar as autobiographical context is considered, as in McClelland et al.'s (1995) theory, it serves only as a means to acquire semantic representations. According to that theory and others like it (see Nadel \& Moscovitch, 1997), once semantic knowledge is gleaned from episodes and consolidated in the neocortex, its dependence on hippocampally represented autobiographical knowledge is lost. It is possible that knowledge denoted by common nouns is less likely to be associated with personal memories and contextual details, as compared with knowledge denoted by proper nouns, such as the names of famous people (as we have shown in our study), public events, or geographical locations. Nonetheless, evidence from semantic dementia suggests that AS also is a component of knowledge denoted by common nouns. Furthermore, the work by Ratcliff, McKoon, 
and colleagues discussed earlier (McKoon \& Ratcliff, 1986; McKoon et al., 1986; Ratcliff \& McKoon, 1986) has demonstrated the ease with which episodic associations may become incorporated into semantic memory representations. Recent studies showing hippocampal influences on tests of verbal fluency and semantic memory retrieval (Whatmough, Chertkow, Verret, Whitehead, \& Desousa, in press) also attest to this possibility. It is hoped that future experiments and theories will take into consideration the influence of AS on knowledge and will explore further the nature of its contributions to different types of concepts.

\section{Conclusion}

Through experience, we acquire a wealth of knowledge about people, places, objects, public events, and abstract concepts that must be structured and organized in a way that facilitates efficient retrieval, meaningful integration of related information, and abstraction of general principles on the basis of specific instances. We have proposed that AS-defined as the association of a concept with contextual episodic details and specific personal memories-makes important contributions to the content and organization of semantic memory. We have presented evidence that AS is distinct from concept familiarity and semantic elaboration, and that it interacts closely with emotional salience. Furthermore, we have argued that the autobiographically significant knowledge is episodic in nature and that it contributes to conceptual representations independently of generic, abstract semantic knowledge that is shared across individuals. Concepts that are personally relevant assume a distinct status in long-term memory because they possess this network of rich personal associations and episodic contextual detail, in addition to generic semantic facts. This distinct status is evidenced in our findings of a performance advantage for autobiographically significant famous names on tests of recall, recognition, fame judgment, and speeded reading.

Little experimental research has been directed at exploring the interaction between autobiographical experience and semantic memory, despite recognition of its relevance to current theoretical debates regarding the neurocognitive structure of memory (Cermak \& O'Connor, 1983; Larsen, 1992; Snowden et al., 1996, 1999; Van der Linden et al., 1992; Verfaellie, Croce, \& Milberg, 1995; Westmacott et al., 2001). Our findings provide preliminary insights into this issue, as well as an impetus for further research using a variety of behavioral, clinical, and neuroimaging paradigms.

\section{REFERENCES}

Bil 1 man, D., \& Heit, E. (1988). Observational learning from internal feedback: A simulation of an adaptive learning method. Cognitive Science, 12, 587-625.

Bil 1 man, D., \& Knut son, J. (1996). Unsupervised concept learning and value systematicity: A complex whole aids learning the parts. Journal of Experimental Psychology: Learning, Memory, \& Cognition, 22, 458-475.
Bozeat, S., La mbon Ral ph, M., Pat terson, K., Garrard, P., \& Hodges, J. R. (2000). Non-verbal semantic impairment in semantic dementia. Neuropsychologia, 38, 1207-1215.

Cer mak, L. S., \& O'Connor, M. (1983). The anterograde and retrograde retrieval ability of a patient with amnesia due to encephalitis. Neuropsychologia, 2, 213-234.

$\mathrm{Cl}$ apper, J. P., \& Bower, G. H. (1991). Learning and applying category knowledge in unsupervised domains. In G. H. Bower (Ed.), The psychology of learning and motivation: Advances in research and theory (Vol. 27, pp. 65-108). San Diego: Academic Press.

Col 1 in s, A. M., \& Loft u s, E. F. (1975). A spreading-activation theory of semantic processing. Psychological Review, 82, 407-423.

Col 1 in s, A. M., \& Qu il 1 ian, M. R. (1969). Retrieval time from semantic memory. Journal of Verbal Learning \& Verbal Behavior, 8, 240-247.

Craik, F. I. M., Moroz, T. M., Moscovit ch, M., St uss, D. T., Winocur, G., Tulving, E., \& Kapur, S. (1999). In search of the self: A positron emission tomography study. Psychological Science, 10, 26-34.

El dridge, L. L., Kn owl t on, B. J., Fur man ski, C. S., Bookheimer, S. Y., $\&$ Engel, S. A. (2000). Remembering episodes: A selective role for the hippocampus during retrieval. Nature Neuroscience, 3, 1149-1152.

Est es, W. K. (1994). Classification and cognition. New York: Oxford University Press.

Gardiner, J. M., Ramponi, C., \& Richardson-Kl avehn, A. (2002). Recognition memory and decision processes: A meta-analysis of remember, know, and guess responses. Memory, 10, 83-98.

Gr ah a m, K. S., \& Hodges, J. R. (1997). Differentiating the roles of the hippocampal system and the neocortex in long-term memory storage. Neuropsychology, 11, 77-89.

Gr aham, K. S., Lambon Ral ph, M. A., \& Hodges, J. R. (1997). Determining the impact of autobiographical experience on "meaning": New insights from investigating sports-related vocabulary and knowledge in two cases with semantic dementia. Cognitive Neuropsychology, 14, 801-837.

Graham, K. S., Lambon Ral ph, M. A., \& Hodges, J. R. (1999). A questionable semantics: The interaction between semantic memory and autobiographical experience in semantic dementia. Cognitive Neuropsychology, 16, 689-698.

Hen son, R. N. A., Rugg, M. D., Shal 1 ice, T., Josephs, O., \& Dol an, R. J. (1999). Recollection and familiarity in recognition memory: An event-related functional magnetic resonance imaging study. Journal of Neuroscience, 19, 3962-3972.

Hint z man, D. L. (1990). Human learning and memory: Connections and dissociations. Annual Review of Psychology, 41, 109-139.

Hodges, J. R., \& Graha m, K. S. (1998). A reversal of the temporal gradient for famous person knowledge in semantic dementia: Implications for the neural organisation of long-term memory. Neuropsychologia, 36, 803-825.

Hodges, J. R., \& McCart hy, R. A. (1995). Loss of remote memory: A cognitive neuropsychological perspective. Current Opinion in Neurobiology, 5, 178-183.

Hodges, J. R., Pat t er son, K., \& Tyl er, L. K. (1994). Loss of semantic memory: Implications for the modularity of the mind. Cognitive Neuropsychology, 11, 505-542.

Kl ein, S. B., \& Kihl st rom, J. F. (1986). Elaboration, organization, and the self-reference effect in memory. Journal of Experimental Psychology: General, 115, 26-38.

Kl ein, S. B., \& Loft u s, J. (1988). The nature of self-referent encoding: The contribution of elaboration and organizational processes. Journal of Personality \& Social Psychology, 55, 5-11.

Knowlt on, B. J. (1998). The relationship between remembering and knowing: A cognitive neuroscience approach. Acta Psychologica, 98, 253-266.

Knowlt on, B. J., \& Squ ir e, L. R. (1995). Remembering and knowing: Two different expressions of declarative memory. Journal of Experimental Psychology: Learning, Memory, \& Cognition, 21, 699-710.

Larsen, S. F. (1992). Personal context in autobiographical and narrative memories. In M. A. Conway, D. C. Rubin, \& H. Spinnler (Eds.), Theoretical perspectives on autobiographicalmemory (pp. 53-74). Boston: Kluwer.

Masson, M. E. J. (1995). A distributed memory model of semantic 
priming. Journal of Experimental Psychology: Learning, Memory, \& Cognition, 21, 3-23.

McClell 1 and, J. L., McNaught on, B. L., \& O'Reilly, R. C. (1995). Why there are complementary learning systems in the hippocampus and neocortex: Insights from the successes and failures of connectionist models of learning and memory. Psychological Review, 102, 419-457.

McKoon, G., \& Rat cl iff, R. (1986). Automatic activation of episodic information in a semantic memory task. Journal of Experimental Psychology: Learning, Memory, \& Cognition, 12, 108-115.

McKoon, G., Rat cl iff, R., \& Del 1, G. S. (1986). A critical evaluation of the semantic-episodic distinction. Journal of Experimental Psychology: Learning, Memory, \& Cognition, 12, 108-115.

McRae, K., Cree, G. S., West macot t, R., \& de Sa, V. R. (1999). Further evidence for feature-feature correlations in semantic memory. Canadian Journal of Experimental Psychology, 53, 360-373.

McRae, K., de Sa, V. R., \& Seidenber g, M. S. (1997). On the nature and scope of featural representations of word meaning. Journal of Experimental Psychology: General, 126, 99-130.

Medin, D. L., \& Schaffer, M. M. (1978). Context theory of classification learning. Psychological Review, 85, 207-238.

Nadel , L., \& Moscovit ch, M. (1997). Memory consolidation, retrograde amnesia and the hippocampal complex. Current Opinion in Neurobiology, 7, 217-227.

Rat cl iff, R., \& McKoon, G. (1986). More on the distinction between episodic and semantic memories. Journal of Experimental Psychology: Learning, Memory, \& Cognition, 12, 312-313.

Rips, L. J. (1989). Similarity, typicality, and categorization. In S. Vosniadou \& A. Ortony (Eds.), Similarity and analogicalreasoning (pp. 2159). New York: Cambridge University Press.

Roger s, T. B., Kuiper, N. A., \& Kirker, W. S. (1977). Self-reference and the encoding of personal information. Journal of Personality \& Social Psychology, 35, 677-688.

Rosch, E. (1975). Cognitive representations of semantic categories. Journal of Experimental Psychology: General, 104, 192-233.

Rosch, E. (1978). Principles of categorization. In E. Rosch \& B. B. Lloyd (Eds.), Cognition and categorization (pp. 27-48). Hillsdale, $\mathrm{NJ}$ : Erlbaum.

Rosch, E., \& Mer vis, C. B. (1975). Family resemblances: Studies in the internal structure of categories. Cognitive Psychology, 7, 573-605.

Seidenberg, M. S., \& McClel 1 and, J. L. (1989). A distributed, developmental model of word recognition and naming. Psychological Review, 96, 523-568.

Smit h, E. E., Shoben, E. J., \& Rips, L. J. (1974). Structure and process in semantic memory: A featural model for semantic decisions. Psychological Review, 81, 214-241.

Snowden, J. S., Goul ding, P. J., \& Near y, D. (1989). Semantic dementia: A form of circumscribed cerebral atrophy. Behavioural Neurology, 2, 167-182.

Snowden, J. S., Griffit hs, H. L., \& Neary, D. (1994). Semantic dementia: Autobiographical contribution to preservation of meaning. Cognitive Neuropsychology, 11, 265-288.
Snowden, J. S., Gr iffit hs, H. L., \& Near y, D. (1995). Autobiographical experience and word meaning. Memory, 3, 225-246.

Snowden, J. S., Gr iffit hs, H. L., \& Neary, D. (1996). Semantic-episodic memory interactions in semantic dementia: Implications for retrograde memory function. Cognitive Neuropsychology, 13, 1101-1137.

Snowden, J. S., Gr iff it hs, H. L., \& Neary, D. (1999). The impact of autobiographical experience on meaning: Reply to Graham, Lambon Ralph, and Hodges. Cognitive Neuropsychology, 16, 673-687.

Symons, C. S., \& John son, B. T. (1997). The self-reference effect in memory: A meta-analysis. Psychological Bulletin, 121, 371-394.

Tulving, E. (1972). Episodic and semantic memory. In E. Tulving \& W. Donaldson (Eds.), Organization of memory (pp. 381-403). New York: Academic Press.

Tulving, E. (1983). Elements of episodic memory. Oxford: Oxford University Press.

Tulving, E. (1989). Remembering and knowing the past. American Scientist, 77, 361-367.

Van der Linden, M., de Part z, M., Schil s, J., \& Seron, X. (1992). Semantic and autobiographical memory: Neuropsychological dissociations? In M. A. Conway, D. C. Rubin, \& H. Spinnler (Eds.), Theoretical perspectives on autobiographical memory (pp. 473-494). Boston: Kluwer.

Ver fael 1 ie, M., Croce, P., \& Mil berg, W. P. (1995). The role of episodic memory in semantic learning: An examination of vocabulary acquisition in a patient with amnesia due to encephalitis. Neurocase, 1, 291-304.

War $r$ ingt on, E. K., \& Shall 1 ice, T. (1984). Category specific semantic impairments. Brain, 107, 829-854.

Wel 1 s, G. L., Hoff man, C., \& Enzl e, M. E. (1984). Self- versus otherreferent processing at encoding and retrieval. Personality \& Social Psychology Bulletin, 10, 574-584.

West macot t, R., Bl ack, S. E., Fr eedman, M., \& Moscovit ch, M. (2003). The contribution of autobiographicalexperience to semantic memory: Evidence from Alzheimer's disease, semantic dementia and amnesia. Manuscript submitted for publication.

West macot t, R., Leach, L., Freedman, M., \& Moscovit ch, M. (2001). Different patterns of autobiographical memory loss in semantic dementia and medial temporal lobe amnesia: A challenge to consolidation theory. Neurocase, 7, 37-55.

Wh at mough, C., Chert kow, H., Ver r et, L., Whit eh ead, V., \& Desousa, K. (in press). The hippocampal complex facilitates semantic memory retrieval: Positron emission tomography (PET) studies. Brain \& Cognition.

\section{NOTES}

1. Data were collected between October 2000 and December 2000; thus, "current" refers to the 1999-2000 time period.

2. Even though we used norms to identify the names that have AS to most people, the particular aspects of that significance is unique-one person's memory of what they were doing when they heard of Princess Diana's crash is different from that of another. 
APPENDIX A

High- and Low-R Names as Rated by 65- to 80-Year-Olds

\begin{tabular}{|c|c|c|c|c|c|}
\hline High-R Names & Percent R & Mean Familiarity & Low-R Names & Percent R & Mean Familiarity \\
\hline Adolf Hitler & 96 & 6.78 & Albert Einstein & 16 & 6.76 \\
\hline Bill Clinton & 93 & 6.78 & Bill Gates & 12 & 6.23 \\
\hline Christopher Reeve & 93 & 5.32 & Bob Dole & 10 & 6.00 \\
\hline David Milgaard & 89 & 4.04 & Celine Dion & 20 & 6.78 \\
\hline Duke Ellington & 89 & 6.22 & Dalton McGuinty & 16 & 4.04 \\
\hline Dustin Hoffman & 82 & 6.40 & Dan Quayle & 8 & 6.07 \\
\hline Humphrey Bogart & 98 & 6.78 & David Cassidy & 14 & 5.78 \\
\hline Jack Ruby & 93 & 4.01 & David Peterson & 8 & 4.71 \\
\hline John F. Kennedy & 100 & 7.00 & David Suzuki & 12 & 6.49 \\
\hline John Lennon & 96 & 6.07 & Gordon Lightfoot & 16 & 6.65 \\
\hline Judy Garland & 96 & 6.33 & Jerry Seinfeld & 20 & 6.50 \\
\hline Lee Harvey Oswald & 98 & 4.76 & Jerry Springer & 18 & 5.17 \\
\hline Lucille Ball & 91 & 6.09 & Joe Clark & 18 & 5.84 \\
\hline Marilyn Monroe & 98 & 7.00 & Larry King & 12 & 6.13 \\
\hline Martin Luther King & 94 & 6.44 & Lyndon Johnson & 6 & 5.89 \\
\hline Nicole Brown Simpson & 87 & 4.84 & Magic Johnson & 20 & 6.42 \\
\hline Oliver North & 82 & 5.18 & Michael Jackson & 20 & 6.67 \\
\hline Paul Bernardo & 98 & 5.18 & Mick Jagger & 20 & 6.21 \\
\hline Pierre Trudeau & 91 & 6.08 & Montgomery Clift & 14 & 5.38 \\
\hline Ronald Reagan & 91 & 6.23 & Oprah Winfrey & 20 & 6.82 \\
\hline Tammy Faye Bakker & 80 & 5.25 & Tom Cruise & 18 & 6.25 \\
\hline Terry Fox & 92 & 5.78 & Tom Selleck & 16 & 5.73 \\
\hline Tonya Harding & 82 & 5.18 & Tony Blair & 10 & 5.13 \\
\hline Walter Cronkite & 93 & 6.56 & Whoopi Goldberg & 14 & 6.02 \\
\hline Yitzhak Rabin & 87 & 4.88 & Yasir Arafat & 20 & 5.06 \\
\hline Mean & 92 & 5.81 & Mean & 15 & 5.95 \\
\hline
\end{tabular}

\section{APPENDIX B}

High- and Low-R Names as Rated by 45- to 55-Year-Olds

\begin{tabular}{|c|c|c|c|c|c|}
\hline High-R Names & Percent R & Mean Familiarity & Low-R Names & Percent R & Mean Familiarity \\
\hline Al Gore & 86 & 6.40 & Diana Ross & 16 & 4.98 \\
\hline Anne Bancroft & 80 & 2.26 & Dolly Parton & 20 & 5.50 \\
\hline Barbara Frum & 80 & 4.42 & Donald Trump & 14 & 3.74 \\
\hline Carroll O'Connor & 80 & 3.52 & Eddie Murphy & 12 & 4.28 \\
\hline Donovan Bailey & 82 & 4.28 & George Lucas & 14 & 4.56 \\
\hline Dustin Hoffman & 88 & 5.56 & John Diefenbaker & 6 & 5.58 \\
\hline Frank Sinatra & 86 & 6.38 & Johnny Carson & 18 & 5.54 \\
\hline Jack Kavorkian & 80 & 2.86 & Kathy Lee Gifford & 14 & 2.92 \\
\hline John Belushi & 80 & 4.64 & Larry King & 18 & 5.90 \\
\hline John F. Kennedy & 100 & 6.90 & Margaret Thatcher & 10 & 5.72 \\
\hline John Lennon & 90 & 6.42 & Martha Stewart & 10 & 5.82 \\
\hline Karla Homolka & 92 & 4.00 & Mia Farrow & 18 & 3.44 \\
\hline Lee Harvey Oswald & 90 & 3.84 & Michael Jackson & 16 & 6.26 \\
\hline Leslie Mahaffy & 88 & 2.90 & Mick Jagger & 20 & 5.26 \\
\hline Michael J. Fox & 82 & 4.62 & Oliver Stone & 12 & 2.46 \\
\hline Monica Lewinsky & 88 & 4.02 & Oprah Winfrey & 14 & 5.70 \\
\hline Neil Armstrong & 80 & 4.74 & Pamela Wallin & 8 & 5.90 \\
\hline O.J. Simpson & 98 & 6.62 & Peter Mansbridge & 14 & 5.82 \\
\hline Paul Bernardo & 98 & 4.16 & Robert Redford & 20 & 5.44 \\
\hline Pierre Trudeau & 98 & 6.70 & Robin Williams & 20 & 5.56 \\
\hline Princess Diana & 94 & 6.72 & Shania Twain & 16 & 5.48 \\
\hline Terry Fox & 92 & 2.98 & Stephen King & 12 & 4.60 \\
\hline Walter Matthau & 80 & 4.16 & Tom Hanks & 20 & 5.02 \\
\hline Wayne Gretzky & 88 & 6.72 & Warren Beatty & 18 & 4.54 \\
\hline Yitzhak Rabin & 80 & 3.52 & Whoopi Goldberg & 10 & 5.16 \\
\hline Mean & 87 & 4.77 & Mean & 15 & 5.01 \\
\hline
\end{tabular}

(Manuscript received October 21, 2002;

revision accepted for publication March 29, 2003.) 